\title{
A supply chain model with shortages under inflationary environment
}

\section{Kapil Kumar Bansal*}

Head, Research \& Publication, SRM University, NCR Campus, Ghaziabad, India

\begin{tabular}{|c|c|}
\hline CHRON I C L E & A B S T RACT \\
\hline $\begin{array}{l}\text { Article history: } \\
\text { Received October 20, } 2015 \\
\text { Received in revised format } \\
\text { February 28, } 2016 \\
\text { Accepted March } 42016 \\
\text { Available online } \\
\text { March 6 2016 } \\
\text { Keywords: } \\
\text { Shortages under Inflationary } \\
\text { Environment } \\
\text { Deteriorating }\end{array}$ & $\begin{array}{l}\text { This paper formulates a multi-level supply chain network with a single producer, multi } \\
\text { distributors and multi retailers during a finite planning horizon. The demand rate is assumed } \\
\text { to be exponential function of time; shortages are allowed and completely backlogged. The } \\
\text { stock is assumed to undergo deterioration as soon as it is produced. The production rate is } \\
\text { dependent on demand rate and greater than the demand rate. Optimal solution for the proposed } \\
\text { model is derived and using a numerical example, the behavior of the model is analyzed. }\end{array}$ \\
\hline
\end{tabular}

\section{Introduction}

Inventory models normally consider different sub systems in the supply chain, independently. With the recent advances in communication and information technologies, the integration of these functions is a common phenomenon. Moreover, due to limited resources, increasing competition and market globalization, enterprises are forced to develop supply chain, which could respond quickly to customer needs with minimum stock and maximum service level. The idea of joint total cost of the supplier and the customer was first introduced by Goyal (1976). Later, Cohen and Lee (1988) put forward a model for determining material requirement for all materials at every stage in the supply chain. Pake and Cohen (1993) extended the above study to consider for stochastic sub systems to explore the supply chain system. Goyal and Nebebe (2000) considered a problem of determining economic production from a vendor to a buyer. Wee (2003) developed an integrated inventory model with constant rate of deterioration and multiple deliveries. Lee and $\mathrm{Wu}$ (2006) developed a study on inventory replenishment policies in a two-echelon supply chain system. Ahmed et al. (2007) coordinated a two level supply chain in which they considered production interruptions for restoring of the quality of the production process.

\footnotetext{
* Corresponding author

E-mail address: drkapilbansal25@gmail.com (K.K.Bansal)

(C) 2016 Growing Science Ltd. All rights reserved.

doi: $10.5267 /$ j.uscm.2016.3.002
} 
Several studies have examined the inflationary effect on an inventory policy. Inflation also influences demand of certain products. Buzacott (1975), Misra (1979), Chandra and Bahner (1985) are amongst the first few who studied the concept of inflation with regard to inventory. Moon and Lee (2000) investigated the impact of inflation and unit cost. They developed their model taking both complete backlogging and without backlogging. Chang (2004) deliberated the effects of inflation on an economic order quantity model when the supplier permits a delay in payment by the retailer if the retailer orders a large quantity. Yang (2006) considered two-warehouse partial backlogging inventory models for deteriorating items under inflation. Lo et al. (2007) developed an integrated production and inventory model from the perspectives of both the manufacturer and the retailer assuming a varying rate of deterioration, partial backordering, inflation, imperfect production processes and multiple deliveries.

Although a number of studies have been performed on the supply chain system with inflation but none of the above paper considers the effect of inflation on demand in supply chain system. This is a major drawback in the studies performed till date. Hence, in our present study we undertake to study a supply chain network for a multi echelon system with a single producer, multi distributors and multi retailers. Also we have considered the rate of production to depend on the demand in the market. This way, the whole research caters to put forward some aspects of a supply chain with some real world considerations and market deliberations.

\section{Assumptions and notations}

The following assumptions have been used throughout the study.

1. Single item inventory is assumed.

2. Lead time is zero.

3. Production rate is demand rate dependent, and is greater than the demand rate.

4. There is a single producer, multi distributors and multi retailers.

5 . Deterioration of the inventory sets in as soon as an item is produced.

6. Deterioration rate of the inventory is finite.

7. Shortages are allowed in the system for distributor and retailer.

8. Planning horizon is known and fixed.

9. Deliveries to both the distributors and the retailers are made at fixed interval.

The following notations have been used throughout the study.

$I_{p}(t) \quad$ Inventory level of the producer at any time.

$I_{d}(t)$ Inventory level of the distributor at any time.

$I_{r}(t) \quad$ Inventory level of the retailer at any time.

$P \quad$ Production rate of the inventory by the producer, $P=K D, K>1$.

$D \quad$ Annual demand rate in the whole market, $D=\lambda e^{\alpha t}$ units/year, where ' $\lambda 0^{\prime}$ ' is the initial demand rate and $0 \leq \alpha \leq 1$ is a constant.

$\theta \quad$ Deterioration rate of the inventory, $\theta>0$ and a constant.

$r \quad$ Discount rate, where $r>\alpha$.

$H \quad$ Planning horizon of the supply chain.

$q \quad$ Number of distributors.

$p \quad$ Number of retailers corresponding to each distributor.

$n \quad$ Total number of cycles of the producer in the complete planning horizon.

$n_{d} \quad$ Total number of deliveries from the producer to the distributor in one cycle of producer.

$n_{r} \quad$ Total number of deliveries from the distributor to the retailer in one cycle of distributor.

$T_{i l} \quad$ Time when the production is stopped by the producer.

$T_{i} \quad$ Time when the inventories reduce to zero at the producer's end.

$A_{p} \quad$ Setup cost of the producer per cycle. 
$A_{d} \quad$ Ordering cost of the distributor per cycle.

$A_{r} \quad$ Ordering cost of the retailer per cycle.

$U_{p} \quad$ Unit production cost per item, \$/item.

$U_{d} \quad$ Unit purchase cost for the distributor, \$/unit item.

$U_{r} \quad$ Unit purchase cost for the retailer, \$/unit item.

$C_{p} \quad$ Holding cost of the producer, \$/unit item/unit time.

$C_{d} \quad$ Holding cost of the distributor, \$/unit item/unit time.

$C_{r} \quad$ Holding cost of the retailer, $\$$ unit item/unit time.

$S_{d} \quad$ Shortage cost of the distributor, \$/unit item/unit time.

$S_{r} \quad$ Shortage cost of the distributor, \$/unit item/unit time.

\section{Mathematical model}

The model under study has a single producer who fulfills the requirements of ' $q$ ' distributors, and in turn every distributor satisfies ' $p$ ' retailers and there are ' $p q$ ' retailers. The whole planning horizon has been divided equally into $n$ cycles. The cycle starts at time $t=0$, when the production starts. We assume that there are $n_{d}$ numbers of deliveries made by the producer in any cycle to his distributors, all at equal intervals of time.

\subsection{Retailer's model}

Assuming continuous compounding of inflation, the ordering cost, unit cost of the item, out-of-pocket inventory carrying cost and shortage cost at any time $t$ are

$$
A(t)=A_{r} e^{\alpha t}, U(t)=U_{r} e^{\alpha t}, C(t)=C_{r} e^{\alpha t}, S(t)=S_{r} e^{\alpha t}
$$

The planning horizon $(H)$ has been divided into $n$ equal cycles of length $T$ (i.e. $T=H / n$ ). Let us consider the ith cycle, i.e. $t_{i-1} \leq t \leq t_{i}$, where $t_{0}=0, t_{n}=H, t_{i}-t_{i-1}=T$ and $t_{i}=i T(i=1,2, \ldots ., n)$. At the beginning of the ith cycle, a batch of $q_{i}$ units enters the inventory system from which $s i$ units are delivered towards backorders leaving a balance of $I_{o i}$ units as the initial inventory level of the ith cycle, i.e. $q_{i}=I_{o i}+s_{i}$. Thereafter, as time passes, the inventory level gradually decreasing mainly due to demand and partly due to deterioration and reaches zero at time $t_{i l}$ (Fig 1.). Further, demands during the remaining period of the cycle, i.e. from $t_{i l}$ to $t_{i}$ are backlogged and are fulfilled by a new procurement. Now $t_{i l}=t_{i}-k T$ $=(i-k) H / n$, level of the ith cycle at time $\mathrm{t}\left(t_{i-1} \leq t \leq t_{i, i}=1,2, \ldots ., n\right)$.

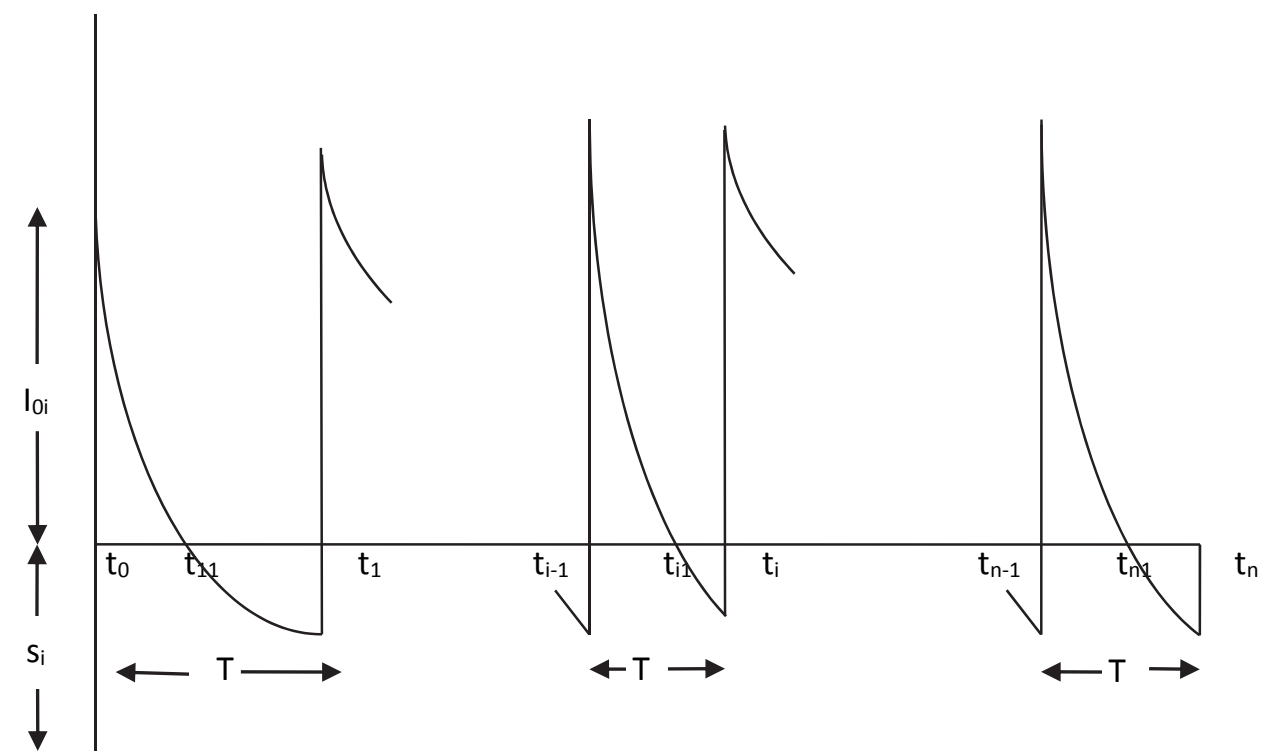

Fig.1. Graphical representation of inventory model of the retailer

The differential equations describing the instantaneous states of $I_{i}(t)$ over $\left(t_{i-1}, t_{i}\right)$ are 


$$
\begin{aligned}
& I_{r i}^{\prime}(t)+\theta I_{i}(t)=-\frac{\lambda_{0}}{p q} e^{\alpha t}, \frac{t_{i-1}}{n_{d} n_{r}} \leq t \leq \frac{t_{i 1}}{n_{d} n_{r}}, \quad i=1,2, \ldots, n \\
& I_{r i}^{\prime}(t)=-\frac{\lambda_{0}}{p q} e^{\alpha t}, \frac{t_{i 1}}{n_{d} n_{r}} \leq t \leq \frac{t_{i}}{n_{d} n_{r}}, \quad i=1,2, \ldots, n
\end{aligned}
$$

The solution of the above differential equations along with the boundary conditions $I_{r i}\left(t_{i-1}\right)=I_{o i}$ and $I_{r i}\left(t_{i 1}\right)=0$ are

$$
I_{r i}(t)= \begin{cases}I_{0 i} e^{\theta\left(\frac{t_{i-1}}{n_{d} n_{r}}-t\right)}-\frac{\lambda_{0} e^{-\theta t}}{p q(\alpha+\theta)}\left(e^{(\theta+\alpha) t}-e^{\left.(\theta+\alpha) \frac{t_{i-1}}{n_{d} n_{r}}\right)}\right. & , \frac{t_{i-1}}{n_{d} n_{r}} \leq t \leq \frac{t_{i 1}}{n_{d} n_{r}} \\ -\frac{\lambda_{0}}{p q \alpha}\left(e^{\alpha t}-e^{\alpha \frac{t_{i 1}}{n_{d} n_{r}}}\right) & , \frac{t_{i 1}}{n_{d} n_{r}} \leq t \leq \frac{t_{i}}{n_{d} n_{r}}\end{cases}
$$

Since $I_{i}\left(t_{i l}\right)=0$ and $I_{i}\left(t_{i}\right)=-s_{i}$, Eqs. (2-3) give

$$
I_{0 i}=\frac{\lambda_{0} e^{-\theta \frac{t_{i-1}}{n_{d} n_{r}}}}{p q(\alpha+\theta)}\left(e^{(\theta+\alpha) \frac{t_{i 1}}{n_{d} n_{r}}}-e^{(\theta+\alpha) \frac{t_{i-1}}{n_{d} n_{r}}}\right)
$$

and

$$
S_{r i}=\frac{\lambda_{0}}{p q \alpha}\left(e^{\alpha \frac{t_{i}}{n_{d} n_{r}}}-e^{\alpha \frac{t_{i 1}}{n_{d} n_{r}}}\right)
$$

Substituting $I_{0 i}$ from Eq. (5), Eq. (4a) becomes

$$
I_{r i}(t)=\frac{\lambda_{0} e^{-\theta t}}{p q(\alpha+\theta)}\left(e^{(\theta+\alpha) \frac{t_{i 1}}{n_{d} n_{r}}}-e^{(\theta+\alpha) t}\right), \frac{t_{i-1}}{n_{d} n_{r}} \leq t \leq \frac{t_{i 1}}{n_{d} n_{r}}
$$

Further, batch size $\mathrm{q}_{\mathrm{i}}$ for the ith cycle is $q_{r i}=I_{0 i}+s_{r i}$. From Eqs. (5-6), we get

$$
q_{r i}=\frac{\lambda_{0} e^{-\theta \frac{t_{i-1}}{n_{d} n_{r}}}}{p q(\alpha+\theta)}\left(e^{(\theta+\alpha) \frac{t_{i 1}}{n_{d} n_{r}}}-e^{(\theta+\alpha) \frac{t_{i-1}}{n_{d} n_{r}}}\right)+\frac{\lambda_{0}}{p q \alpha}\left(e^{\alpha \frac{t_{i}}{n_{d} n_{r}}}-e^{\alpha \frac{t_{i 1}}{n_{d} n_{r}}}\right)
$$

Present worth of ordering cost for the ith cycle, $A_{i}$, is

$$
A_{r i}=A_{r} e^{(\alpha-r) \frac{t_{i-1}}{n_{d} n_{r}}}, \quad i=1,2, \ldots . ., n
$$

Present worth of purchase cost for the ith cycle, $P_{i}$, is

$$
P_{r i}=q_{r i} U_{r} e^{(\alpha-r) \frac{t_{i-1}}{n_{d} n_{r}}}, \quad i=1,2, \ldots . ., n
$$

Present worth of holding cost for the ith cycle, $H_{i}$, is 


$$
\begin{aligned}
H_{r i} & =C\left(t_{i-1}\right) e^{-r \frac{t_{i-1}}{n_{d} n_{r}}} \int_{t_{i-1}}^{t_{i 1}} I_{r i}(t) e^{-r t} d t \\
& =\frac{\lambda_{0} C_{r}}{p q(\alpha+\theta)}\left[\frac{\left(e^{-(r+\theta) \frac{t_{i-1}}{n_{d} n_{r}}} e^{(\alpha+\theta) \frac{t_{i 1}}{n_{d} n_{r}}}-e^{(\alpha-r) \frac{t_{i 1}}{n_{d} n_{r}}}\right)}{(r+\theta)}-\frac{\left(e^{(\alpha-r) \frac{t_{i 1}}{n_{d} n_{r}}}-e^{(\alpha-r) \frac{t_{i-1}}{n_{d} n_{r}}}\right)}{(\alpha-r)}\right] e^{(\alpha-r) \frac{t_{i-1}}{n_{d} n_{r}}}
\end{aligned}
$$

Present worth of shortage cost for the ith cycle, $S_{i}$, is

$$
\begin{aligned}
S_{r i} & =S\left(t_{i-1}\right) e^{-r \frac{t_{i-1}}{n_{d} n_{r}}} \int_{t_{i 1}}^{t_{i}} I_{r i}(t) e^{-r t} d t \\
& =\frac{\lambda_{0} S_{r}}{p q \alpha}\left[\frac{\left(e^{(\alpha+r) \frac{t_{i}}{n_{d} n_{r}}}-e^{(\alpha-r) \frac{t_{i 1}}{n_{d} n_{r}}}\right)}{(\alpha-r)}+\frac{e^{\alpha \frac{t_{i 1}}{n_{d} n_{r}}}}{r}\left(e^{-r \frac{t_{i}}{n_{d} n_{r}}}-e^{-r \frac{t_{i 1}}{n_{d} n_{r}}}\right)\right] e^{(\alpha-r) \frac{t_{i-1}}{n_{d} n_{r}}}
\end{aligned}
$$

Present worth of total cost

The present worth of the total variable cost of the system during the entire time horizon $H$ is given by

$$
T C_{r}=\sum_{i=1}^{n}\left(A_{r i}+P_{r i}+H_{r i}+S_{r i}\right)
$$

\subsection{Distributor's model}

Assumptions for distributor is also continuous compounding of inflation, the ordering cost, unit cost of the item, out-of-pocket inventory carrying cost and shortage cost at any time $t$ are

$$
A(t)=A_{d} e^{\alpha t}, U(t)=U_{d} e^{\alpha t}, C(t)=C_{d} e^{\alpha t}, S(t)=S_{d} e^{\alpha t}
$$

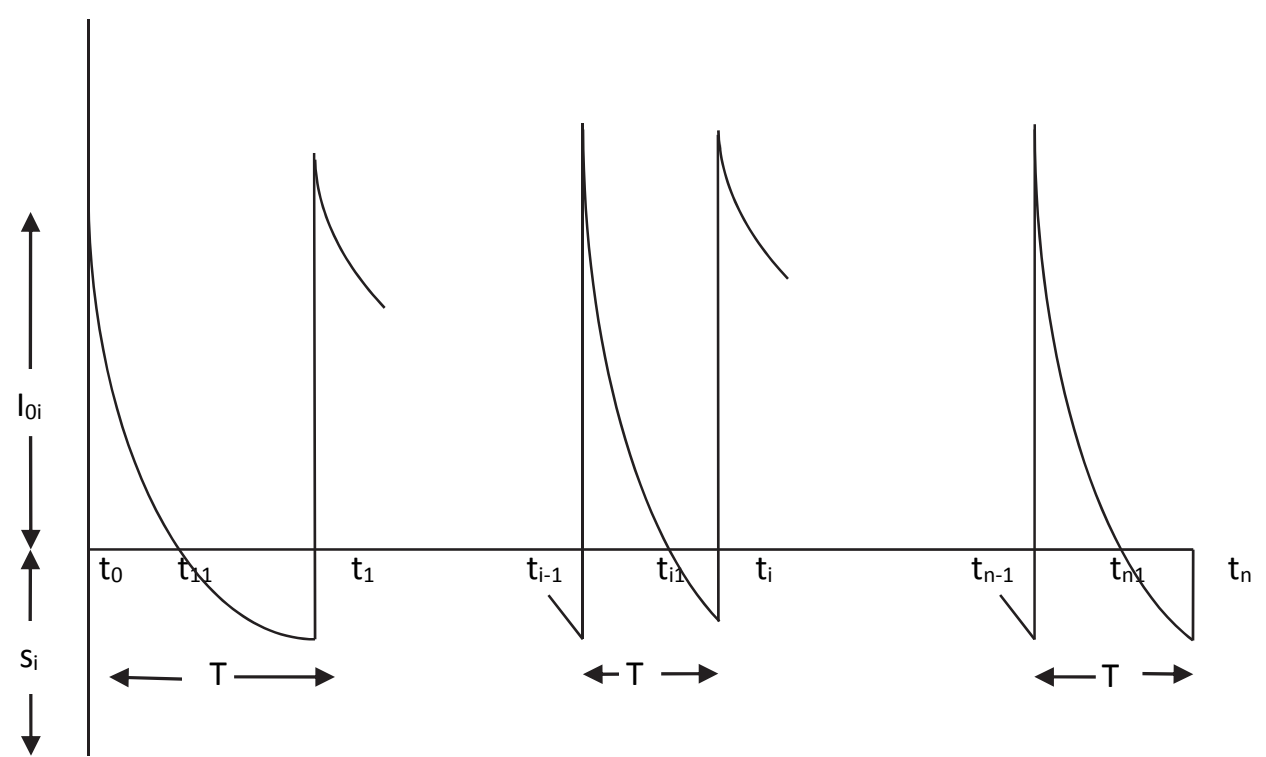

Fig. 2. Graphical representation of inventory model of the distributor 
The differential equations describing the instantaneous states of $I_{i}(t)$ over $\left(t_{i-1}, t_{i}\right)$ are

$$
\begin{array}{lll}
I_{d i}^{\prime}(t)+\theta I_{d i}(t)=-\frac{\lambda_{0}}{q} e^{\alpha t} & , \frac{t_{i-1}}{n_{d}} \leq t \leq \frac{t_{i 1}}{n_{d}}, & \mathrm{i}=1,2, \ldots, \mathrm{n} \\
I_{d i}^{\prime}(t)=-\frac{\lambda_{0}}{q} e^{\alpha t} & , \frac{t_{i 1}}{n_{d}} \leq t \leq \frac{t_{i}}{n_{d}}, & \mathrm{i}=1,2, \ldots, \mathrm{n}
\end{array}
$$

The solution of the above differential equations along with the boundary conditions $I_{d i}\left(t_{i-1}\right)=I_{o i}$ and $I_{d i}\left(t_{i l}\right)=0$ are

$$
I_{d i}(t)= \begin{cases}I_{0 i} e^{\theta\left(\frac{t_{i-1}}{n_{d}}-t\right)}-\frac{\lambda_{0} e^{-\theta t}}{q(\alpha+\theta)}\left(e^{(\theta+\alpha) t}-e^{(\theta+\alpha) \frac{t_{i-1}}{n_{d}}}\right) & , \frac{t_{i-1}}{n_{d}} \leq t \leq \frac{t_{i 1}}{n_{d}} \\ -\frac{\lambda_{0}}{q \alpha}\left(e^{\alpha t}-e^{\alpha \frac{t_{i 1}}{n_{d}}}\right) & , \frac{t_{i 1}}{n_{d}} \leq t \leq \frac{t_{i}}{n_{d}}\end{cases}
$$

Since $I_{d i}\left(t_{i l}\right)=0$ and $I_{d i}\left(t_{i}\right)=-s_{d i}$, Eqs. $(17 \mathrm{a}-17 \mathrm{~b})$ give

$$
I_{0 i}=\frac{\lambda_{0} e^{-\theta \frac{t_{i-1}}{n_{d}}}}{q(\alpha+\theta)}\left(e^{(\theta+\alpha) \frac{t_{i 1}}{n_{d}}}-e^{(\theta+\alpha) \frac{t_{i-1}}{n_{d}}}\right)
$$

and

$$
S_{d i}=\frac{\lambda_{0}}{q \alpha}\left(e^{\alpha \frac{t_{i}}{n_{d}}}-e^{\alpha \frac{t_{i 1}}{n_{d}}}\right)
$$

Substituting $I_{0 i}$ from Eq. (18), Eq. (17a) becomes

$$
I_{d i}(t)=\frac{\lambda_{0} e^{-\theta t}}{q(\alpha+\theta)}\left(e^{(\theta+\alpha) \frac{t_{i 1}}{n_{d}}}-e^{(\theta+\alpha) t}\right), \quad \frac{t_{i-1}}{n_{d}} \leq t \leq \frac{t_{i 1}}{n_{d}}
$$

Further, batch size $q_{i}$ for the ith cycle is $q_{d i}=I_{0 i}+s d i$. From Eqs. (4-5), we get

$$
q_{d i}=\frac{\lambda_{0} e^{-\theta \frac{t_{i-1}}{n_{d}}}}{q(\alpha+\theta)}\left(e^{(\theta+\alpha) \frac{t_{i 1}}{n_{d}}}-e^{(\theta+\alpha) \frac{t_{i-1}}{n_{d}}}\right)+\frac{\lambda_{0}}{q \alpha}\left(e^{\alpha \frac{t_{i}}{n_{d}}}-e^{\alpha \frac{t_{i 1}}{n_{d}}}\right)
$$

Present worth of ordering cost for the ith cycle, $A_{i}$, is

$$
A_{d i}=A_{d} e^{(\alpha-r) \frac{t_{i-1}}{n_{d}}}, \quad i=1,2, \ldots . ., n
$$

Present worth of purchase cost for the ith cycle, $P_{i}$, is

$$
P_{d i}=q_{d i} U_{d} e^{(\alpha-r) \frac{t_{i-1}}{n_{d}}}, \quad i=1,2, \ldots . ., n
$$

Present worth of holding cost for the ith cycle, $H_{i}$, is

$$
\begin{aligned}
& H_{d i}=C\left(t_{i-1}\right) e^{-r \frac{t_{i-1}}{n_{d}} \int_{t_{i-1}}^{t_{i 1}}} I_{i}(t) e^{-r t} d t \\
& =\frac{\lambda_{0} C_{d}}{q(\alpha+\theta)}\left[\frac{\left(e^{-(r+\theta) \frac{t_{i-1}}{n_{d}}} e^{(\alpha+\theta) \frac{t_{i 1}}{n_{d}}}-e^{(\alpha-r) \frac{t_{i 1}}{n_{d}}}\right)}{(r+\theta)}-\frac{\left(e^{(\alpha-r) \frac{t_{i 1}}{n_{d}}}-e^{(\alpha-r) \frac{t_{i-1}}{n_{d}}}\right)}{(\alpha-r)}\right] e^{(\alpha-r) \frac{t_{i-1}}{n_{d}}}
\end{aligned}
$$

Present worth of shortage cost for the ith cycle, $S_{i}$, is

$$
S_{i}=S\left(t_{i-1}\right) e^{-r \frac{t_{i-1}}{n_{d}}} \int_{t_{i 1}}^{t_{i}} I_{i}(t) e^{-r t} d t=\frac{\lambda_{0} S_{d}}{q \alpha}\left[\frac{\left(e^{(\alpha+r) \frac{t_{i}}{n_{d}}}-e^{(\alpha-r) \frac{t_{i 1}}{n_{d}}}\right)}{(\alpha-r)}+\frac{e^{\alpha \frac{t_{i 1}}{n_{d}}}}{r}\left(e^{-r \frac{t_{i}}{n_{d}}}-e^{-r \frac{t_{i 1}}{n_{d}}}\right)\right] e^{(\alpha-r) \frac{t_{i-1}}{n_{d}}}
$$


The present worth of the total variable cost of the system during the entire time horizon $\mathrm{H}$ is given by

$$
T C_{d}=\sum_{i=1}^{n}\left(A_{d i}+P_{d i}+H_{d i}+S_{d i}\right) .
$$

\subsection{Producer's model}

The whole planning horizon has been divided equally into $n$ cycles. The cycle starts at time $t=0$, when the production starts. We assume that there are $n_{d}$ numbers of deliveries made by the producer in any cycle, all at equal intervals of time. Since, we have considered an inflation induced demand; hence, we assume that every lot sent off by the producer is of equal amount. During time interval $\left[0, T_{1}\right]$, the inventory reduces due to both demand and deterioration continuously. At time $t=T_{1}$, the production is stopped, and now the inventory diminishes due to deterioration only, except at the times when a lot is sent off, and then there is a sudden reduction in the inventory level. Hence, the producer's cycle looks like Fig. 3. Assumptions for producer is also continuous compounding of inflation, the setup cost, unit cost of the item, out-of-pocket inventory carrying cost at any time $t$ are

$$
A(t)=A_{p} e^{\alpha t}, U(t)=U_{p} e^{\alpha t}, C(t)=C_{p} e^{\alpha t}, S(t)=S_{p} e^{\alpha t}
$$

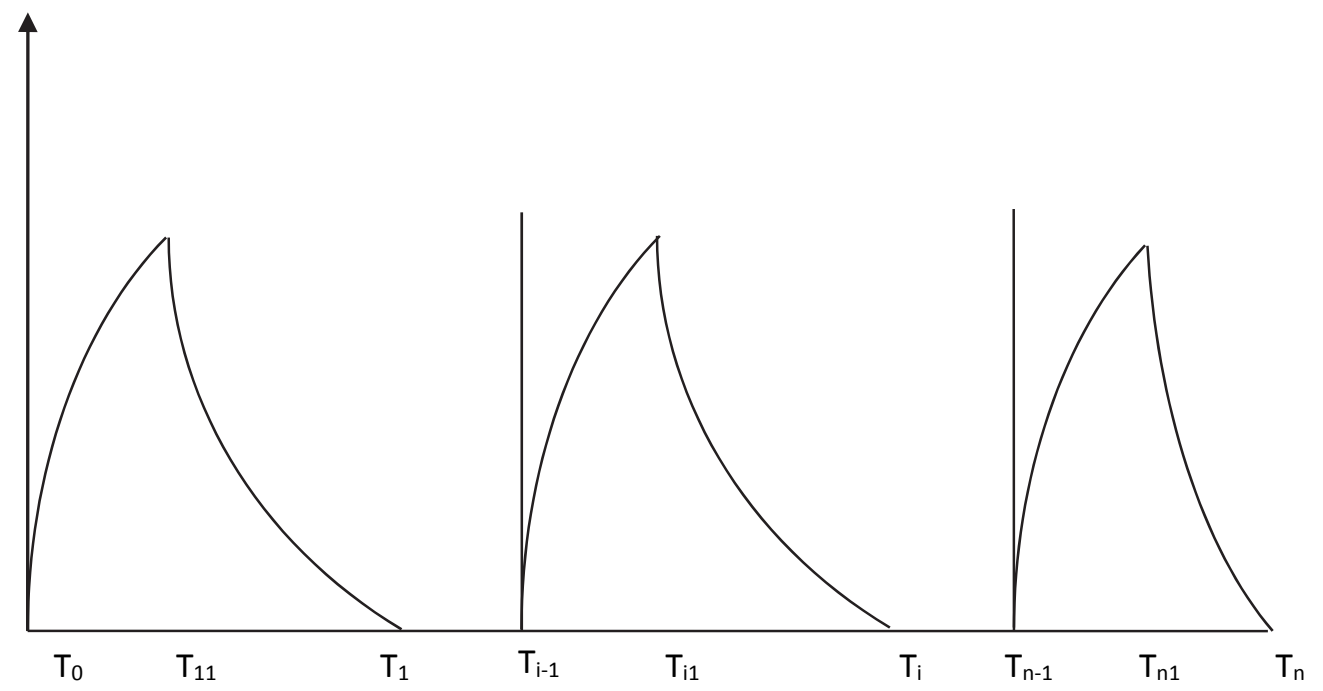

Fig. 3. Graphical representation of the cycles of the producer

The differential equations describing the instantaneous states of $I_{i}(t)$ over $\left(T_{i-1}, T_{i}\right)$ are

$$
\begin{array}{lll}
I_{p 1 i}^{\prime}(t)+\theta I_{p 1 i}(t)=P-\lambda_{0} e^{\alpha t} & , T_{i-1} \leq t \leq T_{i 1}, & \mathrm{i}=1,2, \ldots, \mathrm{n} \\
I_{p 2 i}^{\prime}(t)+\theta I_{p 2 i}(t)=-\lambda_{0} e^{\alpha t} & , T_{i 1} \leq t \leq T_{i}, & \mathrm{i}=1,2, \ldots, \mathrm{n}
\end{array}
$$

The solution of the above differential equations along with the boundary conditions $I_{p l i}(0)=0$ and $I_{p 2 i}\left(T_{i}\right)=0$ are

$$
I_{p i}(t)= \begin{cases}\frac{(K-1) \lambda_{0}}{(\alpha+\theta)}\left(e^{\alpha t}-e^{-\theta t}\right) & , T_{i-1} \leq t \leq T_{i 1} \\ \frac{\lambda_{0} e^{-\theta t}}{\alpha+\theta}\left(e^{(\alpha+\theta) T_{i 2}}-e^{(\alpha+\theta) t}\right) & , T_{i 1} \leq t \leq T_{i}\end{cases}
$$


From $I_{p l i}\left(T_{i l}\right)=q_{p}=I_{p i}(0)$, one can derive the following equation:

$$
\frac{(K-1) \lambda_{0}}{(\alpha+\theta)}\left(e^{\alpha T_{i 1}}-e^{-\theta T_{i 1}}\right)=\frac{\lambda_{0}}{\alpha+\theta}\left(e^{(\alpha+\theta) T_{i 2}}-1\right)
$$

By Taylor's series expansion and assuming small value of $\theta$, one has

$$
T_{i 1}=\frac{T_{i}}{K-1}
$$

We now compute the different costs associated with the producer.

Present worth of ordering cost for the ith cycle, $A$, is

$$
A_{p i}=A_{p} e^{(\alpha-r) T_{i-1}}, \quad i=1,2, \ldots ., n
$$

Present worth of purchase cost for the ith cycle, $P_{i}$, is

$$
P_{p i}=K T_{i 1} U_{p} e^{(\alpha-r) T_{i-1}} \int_{T_{i-1}}^{T_{i 1}} \lambda_{0} e^{-\alpha t} d t, \quad i=1,2, \ldots . ., n
$$

Present worth of holding cost for the ith cycle, $H_{i}$, is

$$
\begin{aligned}
H_{p i}= & C\left(T_{i-1}\right) e^{-r T_{i-1}}\left[\int_{T_{i-1}}^{T_{i 1}} I_{p 1 i}(t) e^{-r t} d t+\int_{T_{i 1}}^{T_{i}} I_{p 2 i}(t) e^{-r t} d t\right] \\
= & \frac{C_{p} \lambda_{0}}{(\alpha+\theta)}\left[K\left(\frac{e^{(\alpha-r) \frac{T_{i}}{K-1}}}{\alpha-r}-\frac{e^{-(r+\theta) \frac{T_{i}}{K-1}}}{r+\theta}\right)+\left(\frac{e^{(\alpha+\theta) T_{i 2}} e^{-(r+\theta) \frac{T_{i}}{K-1}}}{r+\theta}-\frac{1}{r+\theta}-\frac{e^{(\alpha-r) T_{i}}}{\alpha-r}-\frac{e^{-(r+\theta) \frac{T_{i}}{K-1}}}{r+\theta}\right)\right. \\
& \left.K\left(-\frac{e^{(\alpha-r) T_{i-1}}}{\alpha-r}-\frac{e^{-(r+\theta) T_{i-1}}}{r+\theta}\right)+\left(\frac{e^{(\alpha-r) T_{i-1}}}{\alpha-r}-\frac{e^{-(r+\theta) T_{i-1}}}{r+\theta}\right)\right] e^{(\alpha-r) T_{i-1}}
\end{aligned}
$$

Present worth of total cost

The present worth of the total variable cost of the system during the entire time horizon $\mathrm{H}$ is given by

$$
T C_{p}=\sum_{i=1}^{n}\left(A_{p i}+P_{p i}+H_{p i}\right)
$$

\section{Numerical Illustrations}

The following numerical data has been used to find the optimal solution of the three players, the producer, the distributor and the retailer. First we find the separate optimal solutions for the three individuals and then a combined optimal solution has been arrived at. $r=0.12, \theta=0.01, p=6, q=4$, $\lambda_{0}=1000, \alpha=0.05$. Producer data: $U_{p}=10 C_{p}=1 A_{p}=100 \mathrm{~K}=2$, Distributor data: $U_{d}=20 C_{d}=1 A_{d}=50$, Retailer data: $U_{r}=25 C_{r}=1 A_{r}=50$.

We find the solution for different values of ' $n$ ', ' $n d$ ' and ' $n r$ ' and the total cost of the supplier, distributor and the retailer have been found for every combination of these three variables. From the solution obtained, we find the optimal solution for each one of them, separately. In the end we obtain the optimal solution for the whole supply chain using a commercial software package and Table 1 summarizes the results for various values of $n$. 
Table 1

The results of optimal solutions

\begin{tabular}{|c|c|c|c|c|c|c|c|c|}
\hline \multirow[t]{3}{*}{$\mathrm{n}$} & $\mathrm{T}$ & $\mathrm{n}_{\mathrm{r}}$ & $\mathrm{n}_{\mathrm{d}}$ & $\mathrm{K}$ & $\mathrm{TC}_{\mathrm{r}}$ & $\mathrm{TC}_{\mathrm{d}}$ & $\mathrm{TC}_{\mathrm{p}}$ & $\mathrm{TC}$ \\
\hline & 1 & 3 & 5 & 0.00955 & 119.675 & 1060.96 & 5163.45 & 6344.08 \\
\hline & & 1 & 1 & 0.00984 & 1144.0 & 5326.13 & 9899.21 & 16369.34 \\
\hline \multirow[t]{3}{*}{1} & & 2 & 4 & 0.00960 & 181.018 & 1317.14 & 4100.84 & 5598.998 \\
\hline & & 3 & 4 & 0.00953 & 137.165 & 1747.16 & 6545.77 & 8430.095 \\
\hline & & 6 & 2 & 0.00951 & 137.165 & 2618.71 & 7278.51 & 10034.385 \\
\hline \multirow[t]{3}{*}{$\mathrm{n}$} & $\mathrm{T}$ & $\mathrm{n}_{\mathrm{r}}$ & $\mathrm{n}_{\mathrm{d}}$ & $\mathrm{K}$ & $\mathrm{TC}_{\mathrm{r}}$ & $\mathrm{TC}_{\mathrm{d}}$ & $\mathrm{TC}_{\mathrm{p}}$ & $\mathrm{TC}$ \\
\hline & 0.5 & 3 & 5 & 0.00955 & 134.687 & 600.943 & 1975.67 & 2711.3 \\
\hline & & 1 & 1 & 0.00984 & 625.14 & 2627.09 & 5010.40 & 8262.63 \\
\hline \multirow[t]{3}{*}{2} & & 2 & 4 & 0.00960 & 165.076 & 726.529 & 1956.89 & 2848.495 \\
\hline & & 3 & 4 & 0.00953 & 143.366 & 726.529 & 1978.92 & 2848.815 \\
\hline & & 6 & 2 & 0.00951 & 143.366 & 726.71 & 2010.56 & 2880.636 \\
\hline \multirow[t]{3}{*}{$\mathrm{n}$} & $\mathrm{T}$ & $\mathrm{n}_{\mathrm{r}}$ & $\mathrm{n}_{\mathrm{d}}$ & $\mathrm{K}$ & $\mathrm{TC}_{\mathrm{r}}$ & $\mathrm{TC}_{\mathrm{d}}$ & $\mathrm{TC}_{\mathrm{p}}$ & $\mathrm{TC}$ \\
\hline & 0.33 & 3 & 5 & 0.00955 & 172.845 & 480.021 & 1610.23 & 2263.085 \\
\hline & & 1 & 1 & 0.00984 & 493.725 & 1805.15 & 3100.78 & 5399.655 \\
\hline \multirow[t]{3}{*}{3} & & 2 & 4 & 0.00960 & 192.842 & 562.605 & 1789.47 & 2544.917 \\
\hline & & 3 & 4 & 0.00953 & 178.557 & 562.605 & 1809.66 & 2550.822 \\
\hline & & 6 & 2 & 0.00951 & 178.557 & 975.995 & 2189.18 & 3343.732 \\
\hline \multirow[t]{3}{*}{$\mathrm{n}$} & $\mathrm{T}$ & $\mathrm{n}_{\mathrm{r}}$ & $\mathrm{n}_{\mathrm{d}}$ & $\mathrm{K}$ & $\mathrm{TC}_{\mathrm{r}}$ & $\mathrm{TC}_{\mathrm{d}}$ & $\mathrm{TC}_{\mathrm{p}}$ & $\mathrm{TC}$ \\
\hline & 0.25 & 3 & 5 & 0.00955 & 217.275 & 449.815 & 1565.60 & 2232.69 \\
\hline & & 1 & 1 & 0.00984 & 459.431 & 1450.62 & 2845.19 & 4755.241 \\
\hline \multirow[t]{3}{*}{4} & & 2 & 4 & 0.00960 & 232.393 & 512.293 & 1742.23 & 2486.916 \\
\hline & & 3 & 4 & 0.00953 & 221.594 & 512.293 & 1799.45 & 2533.337 \\
\hline & & 6 & 2 & 0.00951 & 221.594 & 824.828 & 2045.89 & 3092.312 \\
\hline \multirow[t]{3}{*}{$\mathrm{n}$} & $\mathrm{T}$ & $\mathrm{n}_{\mathrm{r}}$ & $\mathrm{n}_{\mathrm{d}}$ & $\mathrm{K}$ & $\mathrm{TC}_{\mathrm{r}}$ & $\mathrm{TC}_{\mathrm{d}}$ & $\mathrm{TC}_{\mathrm{p}}$ & $\mathrm{TC}$ \\
\hline & 0.2 & 3 & 5 & 0.00955 & 263.796 & 449.744 & 1589.71 & 2303.25 \\
\hline & & 1 & 1 & 0.00984 & 457.02 & 1249.19 & 3545.95 & 2852.16 \\
\hline \multirow[t]{3}{*}{5} & & 2 & 4 & 0.00960 & 275.868 & 499.687 & 1688.22 & 2463.775 \\
\hline & & 3 & 4 & 0.00953 & 267.245 & 499.687 & 1675.89 & 2442.822 \\
\hline & & 6 & 2 & 0.00951 & 267.245 & 749.449 & 1989.34 & 3006.034 \\
\hline
\end{tabular}

\section{Observations}

The objective of our study is to derive the optimal number of delivery for the producer, distributor and the retailer. Using the solution procedure, the computational result for the optimal solution is given in Table 1.

1. Optimal solution for the retailer is $n=1, n_{d}=5, n_{r}=3$. For the distributor it is $n=5, n_{d}=3, n_{r}=5$ while for the producer, it is $n=4, n_{d}=5, n_{r}=3$. The overall optimal solution which ultimately minimizes the cost across the whole supply chain is $n=4, n_{d}=5, n_{r}=3$.

2. The total cost for the system has been computed for one producer, four distributors and twenty four retailers.

Hence, we observe that in spite of the fact that individual optimal solutions are attained different, but the final optimal for the complete supply chain is very different from the sub optimal solutions.

\section{Conclusion}

In this chapter we first formulated an inventory model with the assumptions that demand is induced by inflation and shortages over a finite planning horizon. Presence of inflation in cost and its impact on demand suggest larger cycle length. As inflation goes up the value of money decreases, which erodes the future worth of savings and suggests more current spending. Usually, these spending are on 
peripherals and luxury items that give rise to demand of these items. A numerical example is used to demonstrate the feasibility and properties of the proposed integration model in this chapter.

\section{References}

Bhunia, A. K., \& Maiti, M. (1994). A two warehouse inventory model for a linear trend in demand. Opsearch, 31, 318-318.

Buzacott, J. A. (1975). Economic order quantities with inflation. Operational Research Quarterly, 26(3), 553-558.

Chang, C. T. (2004). An EOQ model with deteriorating items under inflation when supplier credits linked to order quantity. International Journal of Production economics, 88(3), 307-316.

Chandra, M. J., \& Bahner, M. L. (1985). The effects of inflation and the time value of money on some inventory systems. International Journal of Production Research, 23(4), 723-730.

Cohen, M. A., \& Lee, H. L. (1988). Strategic analysis of integrated production-distribution systems: Models and methods. Operations Research,36(2), 216-228.

Goyal, S. K. (1977). An integrated inventory model for a single supplier-single customer problem. The International Journal of Production Research,15(1), 107-111.

Goyal, S. K., \& Nebebe, F. (2000). Determination of economic production-shipment policy for a single-vendor-single-buyer system. European Journal of Operational Research, 121(1), 175-178.

Kar, S., Bhunia, A. K., \& Maiti, M. (2001). Deterministic inventory model with two levels of storage, a linear trend in demand and a fixed time horizon.Computers \& Operations Research, 28(13), 13151331.

Lee, H. T., \& Wu, J. C. (2006). A study on inventory replenishment policies in a two-echelon supply chain system. Computers \& Industrial Engineering,51(2), 257-263.

Lo, S. T., Wee, H. M., \& Huang, W. C. (2007). An integrated production-inventory model with imperfect production processes and Weibull distribution deterioration under inflation. International Journal of Production Economics,106(1), 248-260.

Misra, R. B. (1979). A note on optimal inventory management under inflation.Naval Research Logistics Quarterly, 26(1), 161-165.

Moon, I., \& Lee, S. (2000). The effects of inflation and time-value of money on an economic order quantity model with a random product life cycle.European Journal of Operational Research, 125(3), 588-601.

Murdeshwar, T. M., \& Sathe, Y. S. (1985). Some aspects of lot size model with two levels of storage. Opsearch, 22(4), 255-262.

Pyke, D. F., \& Cohen, M. A. (1993). Performance characteristics of stochastic integrated productiondistribution systems. European Journal of Operational Research, 68(1), 23-48.

Sarma, K. V. S. (1987). A deterministic order level inventory model for deteriorating items with two storage facilities. European Journal of Operational Research, 29(1), 70-73.

Sarma, K. V. S. (1983). A deterministic inventory model with two levels of storage and an optimum release rule. Opsearch, 20(3), 175-180.

El Saadany, A. M., \& Jaber, M. Y. (2008). Coordinating a two-level supply chain with production interruptions to restore process quality. Computers \& Industrial Engineering, 54(1), 95-109.

Yang, P. C., \& Wee, H. M. (2003). An integrated multi-lot-size production inventory model for deteriorating item. Computers \& Operations Research,30(5), 671-682.

Yang, H. L. (2006). Two-warehouse partial backlogging inventory models for deteriorating items under inflation. International Journal of Production Economics, 103(1), 362-370.

Zhou, Y. W., \& Yang, S. L. (2005). A two-warehouse inventory model for items with stock-leveldependent demand rate. International Journal of Production Economics, 95(2), 215-228. 